assist existing services where possible by directing attention to any literature in their fields of which they might otherwise be unaware, though it would be part of the new Library's responsibility to see that attention was given to any gaps in the technical information services which might develop : one such gap had emerged with regard to Russian translations, on which the Library was now spending more than $£ 100,000$. Dealing more particularly with the relations of the new Library to the rest of the library system, Dr. Urquhart said that in the near future some of the larger libraries and the special libraries would be invited to notify the Library systematically about new serials or conference proceedings which they decided not to acquire, but for which they might have some future need. On the collecting side they would invite all libraries to let them know of publications in the National Library's field for which they received an embarrassing volume of requests for inter-library loans. By collecting such material the new Library would help the inter-library loan arrangements to work more smoothly, but at present the potential loan demand on the new Library seemed to be increasing, and Dr. Urquhart thought the tendency was likely to continue, particularly because the new Library's loan service would be faster than the existing services. Accordingly, they were very interested in efforts to tune up the inter-library loan system. $\mathrm{He}$ thought there was no fundamental reason to prevent evolution of a national inter-library loan form using the prepaid flat-rate system for postage.

Irrespective of its effect on inter-library loan procedure, the existence of the National Lending Library for Science and Technology might well have more profound effects, such as producing a demand for a national lending library for the humanities, possibly based on the National Central Library. Dr. Urquhart, however, left this for future consideration and referred them to the relations of the new Library with local libraries, emphasizing that the potentialities of the comprehensive collection of scientific literature at Boston Spa could not be fully utilized unless the potential users in each locality could discover what they wanted to read, that is, unless guides to the literature of science were available locally. We needed a form of co-operation in which local libraries would assist potential users to find out what they wanted to read, and the National Lending Library would, if necessary, supply this literature. It was intended that such co-operation would be based on the idea that each partner in the scheme would pay his own expenses, and they had recently written about this idea to every local authority and technical college in the United Kingdom. At present, however, standards of technical library service available to the public in many areas were not high: a standard which technologists might criticize as inadequate was attained by only eighteen public libraries and seventeen technical college libraries, and in oonsequence the National Library was building up some sets of bibliographical tools to lend to libraries which are considering developing their bibliographical collections. They had also been thinking about relations with the public libraries and about the training of librarians, and in conclusion Dr. Urquhart urged that future policy must be based on the scientific analysis of the facts.

\title{
CHEMICAL DOCUMENTATION
}

\begin{abstract}
CHEMISTS nowadays are increasingly eager to 1 receive new chemical matter "hot from the press" but many find it impossible to cope quickly with the mass of information contained in the many traditional journals appearing almost hourly. A few years ago the Chemical Society made a great effort to save the chemist's time by introducing a monthly publication, Current Chemical Papers, in which some hundreds of selected titles of papers taken from more than four hundred chemical journals of note were set down under their appropriate sections. The undoubted success of Current Chemical Papers has led the American Chemical Society to copy the essentials of the scheme with the publication on an experimental basis of Chemical Titles*.

The major difference is that Chemical Titles is produced by machines and thus may claim a potential wider coverage and give greater detail.

The titles of some five hundred journals, translated where necessary, are punched on to I.B.M. cards together with the authors' names and journal references and are then fed to computers. Within two hours the new journal appears containing three parts. The first part consists of a permuted title index in which key-words from each title have been arranged alphabetically down the centre line of the column. The second part consists of an alphabetical list of

* Chemical Titles. No. 1, April 1960, 101 pp.; No. 2, May 1960 89 pp. Chem. Abs. Service. American Chemical Society
\end{abstract}

first listed authors together with the titles of their current papers published in the selected journals. The third part (in No. 2 only) gives an index of authors other than the first listed for each paper along with the code reference for the paper.

In addition to the key-word, each horizontal line contains as much of the remainder of the title as the machine's programme permits and thus assists in selection of significant titles.

The system is used by scanning vertically the alphabetical key-word list and then, when interest is seized, by reading the horizontal text. When more information is required the reference code on the right-hand side of the entry is noted and located in the alphabetical author index.

The whole system of making the reference code, etc., and for using the system are described fully in the introduction. It is a very clever and easily understood system which appears to work.

The contents of some 550 journals have been dealt with, and it is planned to make a semi-monthly issue of $2,000-3,000$ titles.

A good many improvements have been made in No. 2, especially in editing, and more will be made as experiments proceed and as suggestions and criticisms are received. The printing will need to be much better and larger if possible.

The publication fully justifies the claim that it increases "current awareness". It will probably be of 
particular value to the industrial chemist anxious to keep "right up to date on the literature".

The course of such an experimental system will be watched with great interest. Its eventual success may well depend on the cost of its production and it remains to be seen whether American machines directed by Malcolm Dysón can do a cheaper and more useful job for chemical documentation than is being done at present by the carefully selective man- and woman. power behind Current Chemical Papers. M. STACEY

\title{
MEASUREMENT AND CONTROL OF MOIRÉ FRINGES
}

$\mathrm{T}$ HE illustrated booklet "Moiré Fringes for Measurement and Control", prepared by the National Physical Laboratory and the National Engineering Laboratory for members of the machine-tool and engineering industries, gives a brie $s$ account of the essential features of moiré-fringe methods and some of their engineering applications (Pp. 11. London : Department of Scientific and Industrial Research, 1960).

Moiré fringes are the pattern of relatively broad equidistant bands produced when two gratings with equal-line spacings are placed face to face, but with the sets of lines not quite parallel to each other. When one of the gratings is moved in the direction at right angles to the lines on it, the fringes move through exactly one fringe spacing as the fringe moves through one grating-line spacing. The variation in brightness as the fringe moves can be detected by a photoelectric cell and the linear movement can therefore be converted into a corresponding electrical signal. Gratings can be produced with radial lines also and thus angular movement can be measured or recorded electrically. Methods for the production of gratings at a reasonable price in the quantities and sizes for industrial use have recently been developed, and copies of master gratings produced at the National Physical Laboratory and National Engineering Laboratory are now available commercially. For most engineering applications gratings with about 1,000 lines per inch are required, but gratings up to
10 in. long with up to 10,000 lines per inch or even glass gratings up to $3 \mathrm{ft}$. long for special purposes can be produced.

Since moiré fringes are produced by very many accurately spaced grating lines and the effect of any errors of spacing of individual lines is reduced by the averaging process which occurs in the production of fringes, great accuracy in measurement is obtainable by using the fringes. Both analogue and digital systems can be used to handle the photoelectric signals, and various applications related to the automatic positioning of machine tools are described in the booklet. It is emphasized that the successful use of moiré-fringe systems requires specialized optical and electronic techniques and that to obtain maximum advantage from the use of moiré fringes in the machine tool field, close co-operation is required between the mechanical engineer and optical and electronic experts. Future developments of the application of the moiré-fringe technique may revolutionize the design of machine tools and the accuracy of their products.

The secondment of members of the staffs of industrial firms to the National Physical Laboratory and National Engineering Laboratory would be a particularly valuable way of speeding up progress, and the laboratories extend, in the booklet, an invitation to firms with electronic, optical or engineering interests to work with them on projects of mutual interest.

\section{GRAFT VERSUS HOST REACTIONS ON THE CHORIOALLANTOIC MEMBRANE OF THE CHICK EMBRYO}

\author{
By SIR MACFARLANE BURNET, O.M., F.R.S., and DEBORAH BURNET \\ Walter and Eliza Hall Institute of Medical Research, Melbourne, Australia
}

\begin{abstract}
$\mathrm{T}$ HE clonal selection theory of immunity ${ }^{1}$ in its present form postulates that in the normal animal a large proportion (perhaps all) of the mesenchymal cells could be divided into clones, each of which is pre-adapted to react with one or other of two antigenic determinant patterns. (The alternatives of being able to react with one, three or four such determinants have not yet been excluded.) The initial distribution of these reactivities is essentially at random, and in the present context there is no call to discuss how the patterns have arisen or how this random distribution to the ancestors of the marked clones could be accomplished. By hypothesis, in the adult there are no clones which can react with normal accessible components of the individual concermed, but there are present clones representing
\end{abstract}

all types of antigenic determinant not present in the body.

Antibody production is presumed to occur in two phases corresponding (1) to the inductive phase and (2) to the productive phase of orthodox immunological theory. In the inductive phase two processes occur : there is proliferation of the clone to produce many more members and the newly produced cells have an increased reactivity with the corresponding antigenic determinant. In the second phase, renewed contact with the antigenic determinant results in proliferation, conversion to the plasma cell form and production of antibody.

According to orthodox immunological theory (for example, ref. 2), the interpretation of the secondary productive phase is not significantly different 